\title{
Natural Radionuclide Concentrations and Radiological Impact Assessment of River Sediments of the Coastal Areas of Nigeria
}

\author{
Olatunde Michael Oni ${ }^{1}$, Idowu Peter Farai ${ }^{2}$, Ayodeji Oladiran Awodugba ${ }^{1}$ \\ ${ }^{1}$ Department of Pure and Applied Physics, Ladoke Akintola University of Technology, Ogbomoso, Nigeria; ${ }^{2}$ Department of Physics, \\ University of Ibadan, Ibadan, Nigeria. \\ Email: omoni@lautech.edu.ng, olatundeoni@yahoo.com
}

Received November $13^{\text {th }}, 2010$; revised February $8^{\text {th }}$, 2011; accepted March $16^{\text {th }}, 2011$.

\begin{abstract}
This work was carried out to measure the radioactivity level in the coastal areas of Nigeria by gamma counting of river sediment samples and assess the radiological impact associated with the use of the river sediments as building material. The method of gamma spectrometry with a $7.6 \mathrm{~cm}$ by $7.6 \mathrm{~cm} \mathrm{NaI}(\mathrm{Tl})$ detector was employed in determining ${ }^{40} \mathrm{~K},{ }^{238} \mathrm{U}$ and ${ }^{232}$ Th levels in 95 and 38 sediment samples respectively collected from representative sites in the oil producing and non oil producing coastal areas of Nigeria. Results of the samples assayed showed that the radioactivity concentrations of ${ }^{40} \mathrm{~K},{ }^{226} \mathrm{Ra}$ and ${ }^{228} \mathrm{Ra}$ in the sediment samples of oil producing areas range from 95.4 to 160.0; 7.6 to 31.0 and 9.5 to $41.6 \mathrm{~Bq} \cdot \mathrm{kg}^{-1}$, respectively. The respective means were calculated as $122.39 \pm 47.49 ; 18.93 \pm 12.53$ and $29.31 \pm 18.67$ $B q \cdot \mathrm{kg}^{-1}$. In the sediment samples from the non oil producing areas, the respective mean values are $88.48 \pm 8.22,14.87$ \pm 3.51 and $(16.37 \pm 3.87) \mathrm{Bq} \cdot \mathrm{kg}^{-1}$. Statistical analysis of the results showed that there is no significant difference between the radionuclide concentration of the sediment samples from different rivers in the oil producing and non oil producing coastal areas, except for ${ }^{40} \mathrm{~K}$. The values of the natural radionuclide concentrations however translate to the determination of the radiological impact assessment values. The values of the radiological assessment indices obtained were observed to be lower than limits internationally reported and recommended for building materials. It could therefore be reported that the operations of the oil companies in the coastline, involving use of radioactive materials have not contributed adversely to the radioactivity level of the river sediments and that the use of river sediments as building material in the coastal areas of Nigeria poses no radiological risk.
\end{abstract}

Keywords: Radiological Risk Indices, River Sediments In Coastal Area, Gamma Spectrometery

\section{Introduction}

Ionising radiations in any environment is traceable to either natural or artificial sources. The artificial sources are largely due to medical and industrial activities. In the coastal areas of Nigeria, the dominating industry is the oil production and exploration. Apart from medical exposure, the petroleum industry is the largest importer and consumer of radioactive materials. The uses of radioactive sources in the industry cover both upstream and downstream operations such as well-logging, automated ionizing radiation gauge, radiography and application of radiotracers in oil well management, reservoir studies and leak detection in pipelines.

Despite conscious efforts and measures to ensure safety, there is a possibility, based on accident, mishandling of equipment, improper discharge, loss and theft, that radioactive materials of natural and artificial sources may pollute the terrestrial and the aquatic environment of the coastal areas which are mainly networks of rivers and creeks. Following different pathways such as erosion run-off and rainfall, large amount of these radioactive materials end up in the aquatic environment. Due to gravitational settling and other depositional phenomena, the highest proportion of the radioactive materials is mainly found in the sediment compartment of the aquatic ecosystem.

The exposure of man to gamma radiation from these radionuclides in the aquatic environment is not limited to the internal exposure due to ingestion through the consumption of contaminated aquatic foods. The use of river sediments as a constituent of building materials for floor- 
ing, plastering and in moulding bricks in the coastal areas of Nigeria has the probability of increasing the external exposure level to man if such sediments have high concentration of radionuclides.

In other parts of the world, research activities have been done in recent time on the contribution to radiation exposure from building materials [1-4]. Reports on related work on building materials are few and scanty in Nigeria. Among the reported few are [5] and [6]. In 2009, the radiological safety assessment of surface-water dam sediments in the south western Nigeria was performed by [7].

In the building, it has been pointed out that the highest concentrations of radionuclides are found in mineralbased materials such as stone, sand, bricks, cement and sediments [8].Though these radionuclides are known to be widely distributed in the environment, their concentrations have been found and reported [9] to depend on the geological setting of a particular environment, and such they vary from place to place.

The objective of this work however is to determine the radioactivity level of naturally occurring ${ }^{40} \mathrm{~K},{ }^{238} \mathrm{U}$ and ${ }^{232} \mathrm{Th}$ in river sediments across the oil producing coastal areas of Nigeria. The measured radioactivity concentra- tion would thereafter translate to the calculation of the impact indices in order to assess the radiological implication of the use of sediments as a constituent of building materials in the area, which for over four decades have been witnessing the use of various types and strengths of radionuclide by the oil companies [10] being accused of polluting the environment of the coastal area in various ways and degrees.

\section{Materials and Methods}

Sediment samples were collected at different points along twenty major rivers in the oil producing coastal area while seven locations were samples for the non oil producing area. The spacing of the points, which vary between 100 and 500 metres was determined largely by accessibility. Conscious efforts were made to sample around operational sites of the oil companies at locations not exceeding $1 \mathrm{~km}$ from the operational sites. In all, a total of 133 sediment samples were collected. The map of the areas of sample collection with oil facilities present is shown in Figure 1.

At each sampling location, divers were provided with grab samplers to collect the river sediments which consist

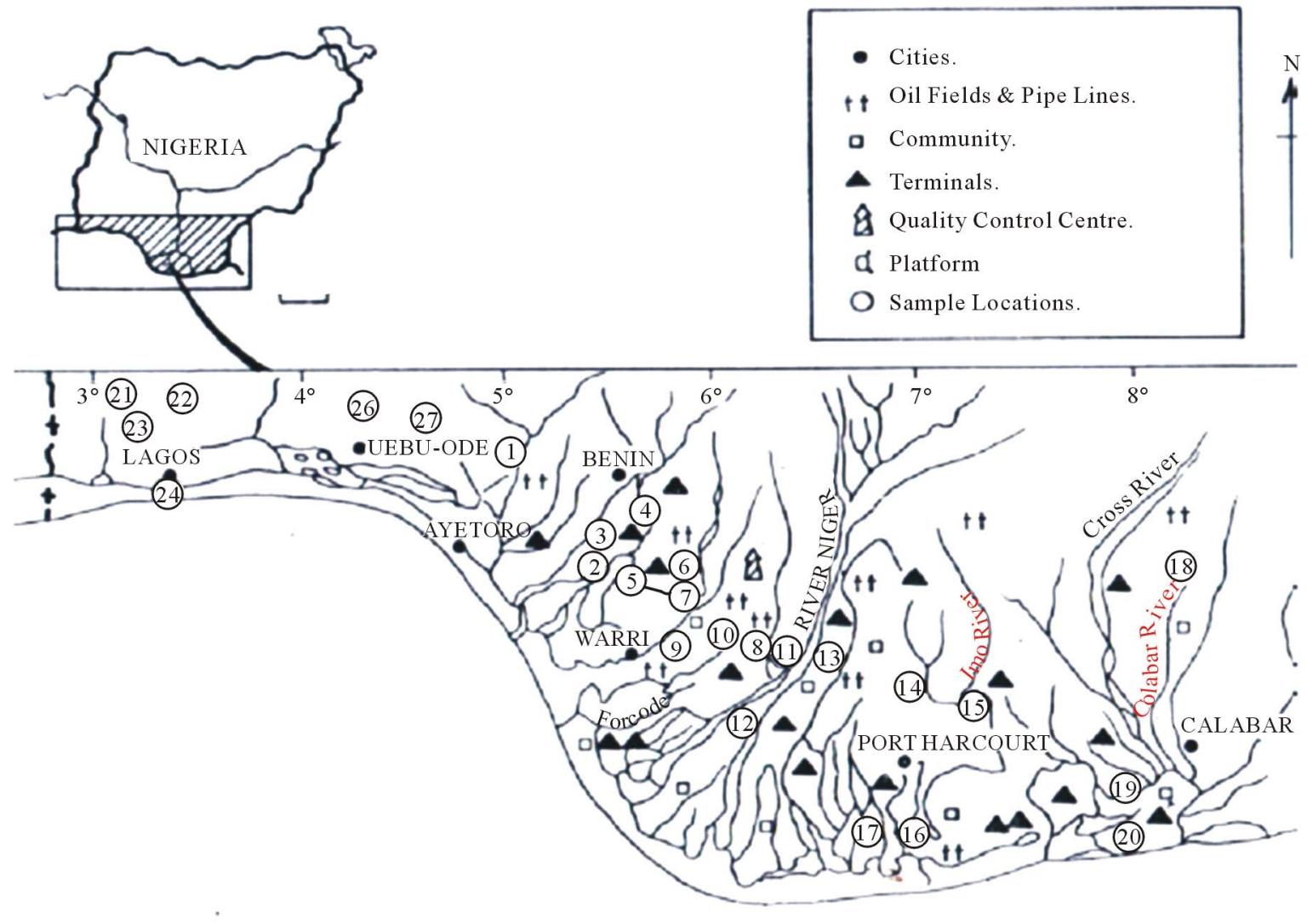

Figure 1. Map of study area showing locations where samples were collected. 
of particulate organic and inorganic matter. After draining off water, each sample was bagged and labeled. The samples were oven dried at a temperature of $105^{\circ} \mathrm{C}$ before pulverization [11] and [12]. The dried samples were then packed $200 \mathrm{~g}$ by mass in labeled cylindrical plastic containers of uniform base diameter of $5.0 \mathrm{~cm}$ which could sit on the $7.6 \mathrm{~cm}$ by $7.6 \mathrm{~cm} \mathrm{NaI}$ (Tl) detector.

The plastic containers were tightly covered, sealed and left for 28 days prior to counting, for attainment of secular equilibrium between ${ }^{238} \mathrm{U}$ and ${ }^{232} \mathrm{Th}$ and their respective progenies $[11,13,14]$.

The radionuclide concentration in the sediment samples was measured with a well calibrated [7] low level gamma counting spectrometer consisting of a $7.6 \mathrm{~cm}$ by $7.6 \mathrm{~cm} \mathrm{NaI}(\mathrm{Tl})$ detector (Model 802 series) manufactured by Canberra Inc. The detector was coupled to a Canberra series 10 plus multi-channel analyzer (MCA) through a preamplifier base. The photopeak regions of ${ }^{40} \mathrm{~K}(1.46 \mathrm{MeV}) ;{ }^{214} \mathrm{Bi}(1.76 \mathrm{MeV})$ and ${ }^{208} \mathrm{Tl}(2.165)$ respectively were used for the analysis ${ }^{40} \mathrm{~K},{ }^{238} \mathrm{U}$ and ${ }^{232} \mathrm{Th}$ in the samples. A region of interest was created around the $0.662 \mathrm{MeV}$ to detect and measure any trace of ${ }^{137} \mathrm{Cs}$ as an index of artificial radionuclides. All samples were counted at a constant geometry and for a constant time of 10 hours.

\section{Radiological Indicators}

Following the measurement of the radionuclide concentrations in the samples, the radium equivalent activity $\left(R a_{e q}\right)$, external hazard index $\left(H_{e x}\right)$ and internal hazard index $\left(H_{i n}\right)$ were used as radiological indicators to estimate the radiological implications of the use of the sediment samples as building materials. Assuming secular equilibrium between ${ }^{40} \mathrm{~K},{ }^{232} \mathrm{Th}$ and ${ }^{238} \mathrm{U}$ and their progenies, $R a_{e q}$, the most frequently used indicators for the assessment of the gamma-ray radiation hazard to humans from environmental samples is defined [15] as

$$
R a_{e q}=\frac{10}{130} C_{K}+\frac{10}{7} C_{T h}+C_{R a}
$$

where $C_{K}, C_{T h}$ and $C_{R a}$ are the respective activity concentrations of ${ }^{40} \mathrm{~K},{ }^{232} \mathrm{Th}$ and ${ }^{226} \mathrm{Ra}$, measured in $\mathrm{Bq} \cdot \mathrm{kg}^{-1}$ of the dry weight.

The external hazard index, $H_{e x}$, commonly used to evaluate the indoor radiation dose rate due to external exposure to gamma radiation from natural radionuclides in building materials can be calculated from the expression of [16] presented as

$$
H_{e x}=\frac{C_{K}}{4810}+\frac{C_{T h}}{259}+\frac{C_{R a}}{370} \leq 1
$$

where $C_{K}, C_{T h}$ and $C_{R a}$ are the activities concentrations of
${ }^{40} \mathrm{~K},{ }^{232} \mathrm{Th}$ and ${ }^{226} \mathrm{Ra}$ (in $\mathrm{Bq} / \mathrm{kg}$ ) respectively. This expression indicates that the value of this index must be less than unity in order to keep the radiation hazard to be insignificant. Thus, the maximum values of $H_{e x}$ equal to unity correspond to the upper limit of $R a_{e q}$ being $370 \mathrm{~Bq} / \mathrm{kg}$.

Considering the hazardous nature of internal exposure to ${ }^{222} \mathrm{Rn}$ and its decay products to the lungs and other respiratory organ, and the fact that reducing the ${ }^{226} \mathrm{Ra}$ to half of its maximum acceptable limit for external exposure only will make $H_{i n}$, the internal hazard index less than unity. Thus $H_{\text {in }}$ is usually estimated as

$$
H_{\text {in }}=\frac{C_{K}}{4810}+\frac{C_{T h}}{259}+\frac{C_{R a}}{185}
$$

Furthermore, following the definition of the absorbed dose rate in indoor air $\mathrm{D}\left(\mathrm{nGy} \cdot \mathrm{h}^{-1}\right)$ given by $[17,18]$ and [19] from natural radionuclides inside a standard room of dimensions $4 \mathrm{~m} \times 5 \mathrm{~m} \times 2.8 \mathrm{~m}$, and following the assumption [20] that the wall thickness is $20 \mathrm{~cm}$ and the density of the aggregates is $2.35 \times 10^{3} \mathrm{~kg} \cdot \mathrm{m}^{-3}$, the fractional contribution to the absorbed dose rate in air from the activity concentrations of the three radionuclides yields

$$
D\left(n G y \cdot h^{-1}\right)=0.080 C_{K}+1.1 C_{T h}+0.92 C_{R a}
$$

The absorbed dose rate in air however translates to the annual effective dose rate indoors for individuals using the values of the absorbed dose rate in indoor air, D $\left(\mathrm{nGy} \cdot \mathrm{h}^{-1}\right)$, the indoor occupancy time and the absorbed dose to the effective dose conversion factor $\left(0.7 \mathrm{~Sv} \cdot \mathrm{Gy}^{-1}\right)$. Assuming an indoor occupancy factor of 0.8 , the annual occupancy time is approximately $7000 \mathrm{~h} \cdot \mathrm{y}^{-1}$. Hence the effective dose rate is estimated using:

$$
\begin{aligned}
H_{E}\left(m S v \cdot y^{-1}\right) & =D\left(n G y \cdot h^{-1}\right) \times 7000\left(h \cdot y^{-1}\right) \\
& \times 0.7\left(S v \cdot G y^{-1}\right) \times 10^{-6}
\end{aligned}
$$

\section{Results and Discussion}

The range for the activity concentration due to ${ }^{40} \mathrm{~K}$ was 95.4 to $160.0 \mathrm{~Bq} \cdot \mathrm{kg}^{-1}$ while those for ${ }^{238} \mathrm{U}$ and ${ }^{232} \mathrm{Th}$ were respectively 7.6 to 31.0 and 9.5 to $41.6 \mathrm{~Bq} \cdot \mathrm{kg}^{-1}$. These ranges, belonging to the same population has been represented by a single mean. To establish this, variation in the radionuclide concentration levels among the twenty (20) sampled rivers in the oil producing area were subjected to statistical test using analysis of variance (ANOVA) at $95 \%$ confidence level. The result $\left(\mathrm{F}_{\text {calculated }}\right.$ $=0.90<\mathrm{F}_{\text {table }}=1.86, \mathrm{p}=0.58$ at $\left.\mathrm{df}=19\right)$ showed that there is no significant difference between the radionuclide concentration of the sediment samples from the different rivers in the oil producing coastal areas. Simi- 
larly, for the non oil producing coastal areas, the result of the ANOVA $\left(\mathrm{F}_{\text {calculated }}=1.56<\mathrm{F}_{\text {table }}=2.99, \mathrm{p}=0.24\right.$ at $\mathrm{df}=6$ ) also revealed a non significant difference. Based on these findings, the representative means of the specific activities of the natural radionuclides in river sediments of the oil producing and non oil producing coastal areas grouped into different states of the country, Nigeria is presented in Table $\mathbf{1}$.

The errors presented with the means of the radioactivity concentrations of ${ }^{40} \mathrm{~K},{ }^{238} \mathrm{U}$ and ${ }^{232} \mathrm{Th}$ in the sediment samples are the standard deviations in the values obtained at different points along each river.

However, since no significant difference exists among all the samples, the grouped mean of the samples from each of the two areas are determined and tested for possible difference based on the area of collection using ttest at 0.05 level of significance. Results of the test presented in Table 2 shows that there exits a significant difference between the means of ${ }^{40} \mathrm{~K}$ in the sediment samples from oil producing coastal areas and those from the non oil producing areas, while ${ }^{238} \mathrm{U}$ and ${ }^{232} \mathrm{Th}$ were observed not to be significantly different at 0.05 level of significance. This observed difference in the ${ }^{40} \mathrm{~K}$ level may be explainable from the geological composition of the sediment which have been reported to be more sedimentary in the Niger Delta region of the coastal areas [21].

The radium equivalent and the results of other radiological indices as shown in Table 3 revealed that despite sediment samples from Cross River having the maximum level of radium equivalent activity, based on the maximum acceptable external dose level of $1.5 \mathrm{mGy}$, corresponding to radium equivalent of $370 \mathrm{~Bq} \cdot \mathrm{kg}^{-1}$ for building materials [22], the values of the mean radium equivalent activity for the sediments from the coastal areas are all below the recommended limit.

Similarly, the observed results of other radiological indicators show that external hazard index, internal hazard index and the annual effective dose rate are all less than unity, hence they are below the recommended limits.

The absorbed dose rate in each of the states of the coastal area of Nigeria is below the worldwide mean of $84 \mathrm{nGy} \cdot \mathrm{h}^{-1}$ for soil matrix as reported in [23].

Table 1. Mean concentrations of the radionuclides in the sediment samples.

\begin{tabular}{|c|c|c|c|c|c|}
\hline \multirow{2}{*}{ State } & \multirow{2}{*}{ No. of rivers } & \multirow{2}{*}{$\begin{array}{l}\text { No of sediment } \\
\text { collected }\end{array}$} & \multicolumn{3}{|c|}{ Mean concentrations $\left(\mathrm{Bq} \cdot \mathrm{kg}^{-1}\right)$} \\
\hline & & & ${ }^{40} \mathrm{~K}$ & ${ }^{238} \mathrm{U}$ & ${ }^{232} \mathrm{Th}$ \\
\hline \multicolumn{6}{|l|}{ Oil producing } \\
\hline Delta & 8 & 39 & $132.80 \pm 15.89$ & $22.37 \pm 6.9$ & $23.04 \pm 1.64$ \\
\hline Bayelsa & 5 & 23 & $122.69 \pm 14.77$ & $15.82 \pm 1.91$ & $21.01 \pm 2.45$ \\
\hline Rivers & 4 & 18 & $109.37 \pm 12.03$ & $16.26 \pm 2.45$ & $21.19 \pm 1.94$ \\
\hline Cross Rivers & 1 & 5 & $99.74 \pm 11.86$ & $30.09 \pm 1.26$ & $41.55 \pm 1.78$ \\
\hline Akwa Ibom & 2 & 10 & $147.38 \pm 12.94$ & $10.12 \pm 1.02$ & $39.76 \pm 1.86$ \\
\hline \multicolumn{6}{|c|}{ Non oil Producing } \\
\hline Ogun & 2 & 10 & $79.65 \pm 11.81$ & $16.46 \pm 1.97$ & $16.93 \pm 1.38$ \\
\hline Lagos & 5 & 28 & $97.31 \pm 16.41$ & $13.28 \pm 2.54$ & $39.76 \pm 1.86$ \\
\hline
\end{tabular}

Table 2. Statistics of test of significance between radioactivity concentrations in sediments from oil producing and non oil producing coastal areas.

\begin{tabular}{lcccc}
\hline & $\mathrm{N}$ & ${ }^{40} \mathrm{~K}\left(\mathrm{~Bq} \cdot \mathrm{kg}^{-1}\right)$ & ${ }^{238} \mathrm{U}\left(\mathrm{Bq} \cdot \mathrm{kg}^{-1}\right)$ & ${ }^{232} \mathrm{Th}^{\left(\mathrm{Bq} \cdot \mathrm{kg}^{-1}\right)}$ \\
\hline Oil producing & 20 & $122.39 \pm 47.49$ & $18.93 \pm 12.53$ & $29.31 \pm 18.67$ \\
Non-oil producing & 7 & $88.48 \pm 8.22$ & $14.87 \pm 3.51$ & $16.37 \pm 3.87$ \\
$\mathrm{t}_{\text {calculated }}$ & & 3.28 & 0.93 & 1.66 \\
$\mathrm{t}_{\text {table }}(\alpha=0.05, \mathrm{df}=25)$ & 1.71 & 1.71 & 1.71 \\
$\mathrm{p}$ value & 0.001 & 0.180 & 0.054 \\
\hline
\end{tabular}


Table 3. Values of the radiological indices.

\begin{tabular}{|c|c|c|c|c|c|}
\hline State & $\mathrm{Ra}_{\mathrm{eq}}$ & $\mathrm{H}_{\mathrm{ex}}\left(\mathrm{Bq} \cdot \mathrm{kg}^{-1}\right)$ & $\mathrm{H}_{\mathrm{in}}\left(\mathrm{Bq} \cdot \mathrm{kg}^{-1}\right)$ & $\mathrm{D}\left(\mathrm{nGy} \cdot \mathrm{h}^{-1}\right)$ & $\mathrm{H}_{\mathrm{E}}\left(\mathrm{mSv} \cdot \mathrm{y}^{-1}\right)$ \\
\hline \multicolumn{6}{|c|}{ Oil producing } \\
\hline Delta & 65.49 & 0.177 & 0.237 & 56.54 & 0.277 \\
\hline Bayelsa & 55.27 & 0.149 & 0.192 & 47.48 & 0.232 \\
\hline Rivers & 54.94 & 0.148 & 0.192 & 47.01 & 0.230 \\
\hline Cross Rivers & 97.11 & 0.262 & 0.343 & 81.36 & 0.398 \\
\hline Akwa Ibom & 78.25 & 0.211 & 0.238 & 64.83 & 0.317 \\
\hline \multicolumn{6}{|c|}{ Non oil producing } \\
\hline Ogun & 46.77 & 0.126 & 0.170 & 40.13 & 0.196 \\
\hline Lagos & 43.35 & 0.117 & 0.153 & 37.39 & 0.183 \\
\hline
\end{tabular}

\section{Conclusions}

The natural radioactivity concentrations of a total of 133 samples of sediment collected from twenty-seven(27) major rivers in the coastal areas of Nigeria have been determined.

Statistical analysis of the results showed that there is no significant difference between the radionuclide concentration of the sediment samples from different rivers in the oil producing and non oil producing coastal areas except for ${ }^{40} \mathrm{~K}$. The values of these natural radionuclide concentrations however translate to the determination of the radiological impact assessment values. The values of the radiological assessment indices obtained were observed to be lower than limits internationally reported and recommended for building materials. It could therefore be reported that the operations of the oil companies in the coastline, involving use of radioactive materials have not contributed adversely to the radioactivity level of the river sediments and that the use of river sediments as building material in the coastal areas of Nigeria poses no radiological risk. As no artificial radionuclide is observed in the samples assayed, the results presented in this work may thus serve as yardstick for future work in this coastal area.

\section{REFERENCES}

[1] M. Sharaf, M. Mansy, El Sayed and E. Abbas, "Natural Radioactivity and Radon Exhalation Rate in Building Materials Used in Egypt," Radiation Measurements, Vol. 31, No. 1-6, 1999, pp. 491-495. doi:10.1016/s1350-4487(99)00206-1

[2] A. K. Sam and N. Abbas, "Assessment of Radioactivity and the Associated Hazards in Local and Imported Cement Types Used in Sudan," Radiation Protection Dosimetry, Vol. 93, No. 3, 2001, pp. 275-277.
[3] J. Al-Jundi, W. Salah, M. S. Bawa’aneh and F. Afaneh, "Exposure to Radiation from the Natural Radioactivity in Jordanian Building Materials," Radiation Protection Dosimetry, Vol. 118, No. 1, 2005, pp. 93-96. doi:10.1093/Rpd/Nci332

[4] L. Xinwei, W. Lingqing and J. Xiaodan, "Radiometric Analysis of Chinese Commercial Granites," Journal of Radioanalytical and Nuclear Chemistry, Vol. 267, No. 3, 2006, pp. 669-673. doi:10.1007/S10967-006-0101-1

[5] I. P. Farai and J. A. Ademola, "Radium Equivalent Activity Concentrations in Concrete Building Blocks in Eight Cities in Southwestern Nigeria," Journal Environmental Radioactivity, Vol. 79, 2005, No. 2, pp. 119-125. doi:10.1016/J.Jenvrad.2004.05.016

[6] I. P. Farai and J. E. Ejeh, "Radioactivity Concentrations in Common Brands of Cement in Nigeria," Radioprotection, Vol. 41, No. 4, 2006, pp. 455-462. doi:10.1051/Radiopro:2006020

[7] I. P. Farai and M. O. Isinkaye, "Radiological Safety Assessment of Surface Water Dam Sediments Used as Building Materials in Southwestern Nigeria,” Journal of Radiological Protection, Vol. 29, No. 1, 2009, pp. 85-93. doi:10.1088/0952-4746/29/1/006

[8] T. Turtiainen, K.Salahel-Din, S. Klemola And A. P. Sihvonen, "Collective Effective Dose by the Population of Egypt from Building Materials,” Journal of Radiological Protection, Vol. 28, No. 2, 2008, pp. 223-232. doi:10.1088/0952-4746/28/2/006

[9] M. Iqba, M. Tufail and S. M. Mirza, "Measurement of Natural Radioactivity in Marble Found in Pakistan Using a Nai(Tl) Gamma-Ray Spectrometer,” Journal of Environmental Radioactivity, Vol. 51, No. 2, 2000, pp. 255-265. doi:10.1016/S0265-931x(00)00077-1

[10] S. A. Elegba, "Uses of Radioactive Sources in the Petroleum Industry," Proceedings of Workshop on Radiation Safety in the Nigeria Petroleum Industry, Lagos, June 23-25, 1993, pp. 20-34.

[11] N. N. Alam, M. I. Chowdhury, M. Kamal, S. Ghose, N. 
Mahmmod, A. K. M. A. Matin and S. Q. Saikat, "Radioactivity in Sediments of The Karnaphuli River Estuary and Bay of Bengal,” Health Physics, Vol. 73, No. 2, 1997, pp. 385-387.doi:10.1097/00004032-199708000-00013

[12] J. M. Gody, L. A. Schuch, D. J. R. Nordemann, V. R. G. Reis, M. Ramalho, J. C. Recio, R. R. A. Brito and M. A. Olech, “ ${ }^{137} \mathrm{Cs},{ }^{226,228} \mathrm{Ra},{ }^{210} \mathrm{~Pb}$ And ${ }^{40} \mathrm{~K}$ Concentrations in Antarctic Soil, Sediment and Selected Moss and Lichen Samples," Journal of Environmental Radioactivity, Vol. 41, No. 1, 1998, pp. 33-45. doi:10.1016/S0265-931X(97)00084-2

[13] G. G. Pyle and F. V. Clulow, "Non-Linear Radionuclide Transfer from the Aquatic Environment to Fish," Health Physics, Vol. 73, No. 3, 1997, pp. 488-493. doi:10.1097/00004032-199709000-00007

[14] H. Papaefthymiou, G. Papatheodorou, A. Moustakli, D. Christodoulou and M. Geraga, "Natural Radionuclides And ${ }^{137}$ Cs Distributions and Their Relationship with Sedimentological Processes in Patras Harbour," Greece Journal of Environmental Radioactivity, Vol. 94, No. 2, 2007, pp. 55-74.

[15] J. Bereka and P. Matthew, "Natural Radioactivity of Australian Building Materials, Industrial Wastes and By-Products,” Health Physics. Vol. 48, No. 1, 1985, pp. 87-95. doi:10.1097/00004032-198501000-00007

[16] Z. Hamzah, S. Ahmad, H. M. Noor and D. E. She, "Surface Radiation Dose and Radionuclide Measurement in Ex-Tin Mining Area, Kg Gajah, Perak,” The Malaysian Journal of Analytical Sciences, Vol. 12, No. 2, 2008, pp. 419-431.
[17] United Nations Scientific Committee on Effects of Atomic Radiation (UNSCEAR), "Sources and Effects of Ionizing Radiation, Annex A,” New York, 1993, pp. 33-89.

[18] European Commission (EC), “European Commission Report on Radiological Protection Principles Concerning the Natural Radioactivity of Building Materials Radiation Protection No. 112,” Luxembourg, 1999.

[19] C. Papastefanou, S. Stoulos and M. Manolopculou, "The Radioactivity of Building Materials,” Journal of Radioanalytical and Nuclear Chemistry, Vol. 266, No. 3, 2005, pp. 367-372. doi:10.1007/s10967-005-0918-z

[20] S. Turhan and L. Gunduz, "Determination of Specific Activity of ${ }^{226} \mathrm{Ra},{ }^{232} \mathrm{Th}$ and ${ }^{40} \mathrm{~K}$ for Assessment of Radiation Hazards from Turkish Pumice Samples," Journal of Radiological Protection, Vol. 99, No. 2, 2008, pp. 332-342. doi:10.1016/j.jenvrad.2007.08.022

[21] N. N. Jibiri, “Application of in-situ Gamma Ray Spectrometry in Baseline Studies of Outdoor Radiation Exposure Levels in Nigeria,” Ph.D. Dissertation, University of Ibadan, Ibadan, 2000.

[22] Matiullah, A. Ahad, S. Rehman, S. Rehman and M. Faheem, "Measurement of Radioactivity in Soil of Bahawapur Division, Pakistan,” Radiation Protection Dosimetry, Vol. 112, No. 3, 2004, pp. 443-447. doi:10.1093/rpd/nch409

[23] United Nations Scientific Committee on Effects of Atomic Radiation (UNSCEAR), "Sources and Effects of Ionizing Radiation, Annex B,” New York, 2000, pp. 3-17. 